\title{
PRÁTICAS CULTURAIS DE CUIDADOS DE MULHERES MÃES DE RECÉM-NASCIDOS DE RISCO DO SUL DO BRASIL
}

\author{
High Risk Newborn Mother's Cultural Practices of Caring in \\ Southern Brazil
}

\section{Prácticas Culturales de Cuidados de Mujeres Madres de Recién Nacidos de Riesgo en el sur del Brasil}

\author{
Ana Rosa Müller Iserhard ${ }^{1}$ \\ Eliane Tatsch Neves ${ }^{3}$
}

\author{
Maria de Lourdes Denardin Budó ${ }^{2}$ \\ Marcio Rossato Badke ${ }^{4}$
}

\section{RESUMO}

As questões atuais relacionadas com a saúde da mulher visam atingir um novo enfoque de integralidade capaz de sobrepor os efeitos limitantes de um modelo biomédico em saúde, sem considerar os aspectos vivenciais e culturais das mulheres e suas famílias. Este estudo objetivou compreender a influência do contexto cultural no desenvolvimento da gestação e no cuidado ao bebê de mulheres mães de recém-nascidos de risco. Trata-se de estudo exploratório-descritivo, desenvolvido a partir de entrevistas com puérperas internadas em uma maternidade no sul do Brasil. Após análise temática dos dados, emergiram duas categorias principais: contexto sociocultural influenciando o período gestacional e os saberes populares no cuidado com o bebê. Os resultados apontaram que não houve, na maioria das vezes, a compreensão da mulher em seu todo, sua visão de mundo e sua maneira de pensar, sentir e agir. Nas questões de conflito, o conhecimento profissional prevaleceu sobre o popular.

Palavras-chave: Saúde da Mulher. Saúde da Criança. Família. Cuidados de Enfermagem. Cultura

\begin{abstract}
Nowadays, the issues related to woman health, seek to get a new integrality focus. It will be able to go beyond the limited effects of a biomedical model in health. Not considering the life experience and cultural aspects of the women and their family. This study aimed to understand the influence of the cultural context during pregnancy and in the baby's care among high risk newborn mothers. It is an exploratory-descriptive study. High risk newborn mothers hospitalized in a maternity in the southern Brazil were interviewed. After thematic analyses two main categories emerged: socio-cultural context influencing the pregnancy and the popular knowledge in the baby's care. The results showed that the majority, among the women, were not influenced by their culture, thoughts, feelings and actions. In the conflict situations the professional knowledge won the credibility, upon the population.
\end{abstract}

\section{Resumen}

Las cuestiones actuales relacionadas con la salud de la mujer visan alcanzar un nuevo enfoque de integración capaz de sobreponer los efectos limitantes de un modelo biomédico en salud, sin considerar los aspectos vivénciales y culturales de las mujeres y sus familias. Este estudio tiene como objetivo comprender la influencia del contexto cultural en el desarrollo de la gestación y en el cuidado al bebé de mujeres madres de recién nacidos de riesgo. Tratase de estudio exploratoriodescriptivo, desarrollado a partir de entrevistas con puérperas internadas en una maternidad en el sur del Brasil. Después del análisis temático de los datos emergieron dos categorias principales: contexto socio-cultural influenciando el periodo gestacional y los conocimientos populares en el cuidado con el bebé. Los resultados indicaron que no hubo, en la mayoría de las veces, la comprensión de la mujer en su todo, en su visión de mundo y su manera de pensar, sentir y actuar. Las cuestiones de conflicto,y el conocimiento profesional prevalecieron sobre lo popular.
Keywords: Woman health. Children health. Family. Nursing care. Culture.
Palabras clave: Salud de la mujer. Salud del niño. Familia. Atención de enfermería. Cultura.

\footnotetext{
'Enfermeira da Secretaria Municipal de Saúde do Município de Novo Cabrais - RS. Responsável pela Saúde da Mulher, Saúde da Criança, Adolescente e Idoso. Graduada pela Universidade Federal de Santa Maria - UFSM. Brasil. E-mail: annaiser@hotmail.com, ${ }^{2}$ Enfermeira. Professora Adjunta do Departamento de Enfermagem e do Programa de Pós-Graduação em Enfermagem da Universidade Federal de Santa Maria. Doutora em Enfermagem pela Universidade Federal de Santa Catarina - PEN/UFSC. Orientadora do trabalho. Brasil. E-mail: lourdesdenardim@gmail.com, ${ }^{3}$ Enfermeira Pediatra. Professora Adjunta do Departamento de Enfermagem e do Programa de Pós-Graduação em Enfermagem da Universidade Federal de Santa Maria. Doutora em Enfermagem pela Escola de Enfermagem Anna Nery - UFRJ, com Estágio Doutoral pela McGill University, Canadá, com financiamento CAPES.

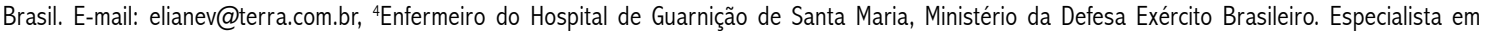
Saúde Pública. Mestrando em Enfermagem - Universidade Federal de Santa Maria. Brasil. E-mail: marciobadke@yahoo.com.br.
} 


\section{INTRODUCÃO}

0 enfoque dado pelo Programa de Assistência Humanizada à Mulher do Ministério da Saúde nos diz que a saúde não deve se restringir ao tradicional conceito de prevenção, diagnóstico, tratamento e reabilitação, mas deve ser abordada também no contexto cultural, histórico e antropológico, no qual estão os indivíduos que se querem ver saudáveis ou livres de doenças'. Desta maneira, as tendências atuais relacionadas à saúde da mulher têm se expandido para além do enfoque reprodutivo, buscando resgatar o cuidado da mulher em sua totalidade. Nesse sentido, a obstetrícia moderna tem atingido resultados importantes na redução da mortalidade e morbidade materna e neonatal, na preservação da vida dos bebês prematuros, no diagnóstico de anormalidades congênitas in utero e outras técnicas nos últimos 50 anos².

Entretanto, apesar de toda evolução tecnológica nesta área, o fato de o nascimento ter sido integrado ao espaço do hospital tornou-o uma prática biomédica, distante do contexto sociocultural das mulheres e suas familias. No mundo ocidental, a medicalização do nascimento ocorrida no final do século XIX e início do século XX $X^{3}$ apresenta uma ênfase exagerada nos aspectos fisiológicos em detrimento dos aspectos psicossociais da gravidez e do parto. Isso representa uma tendência a medicalizar um evento biológico normal, transformando-o em um problema médico e conver tendo, assim, a mulher grávida em um ser passivo e dependente. Neste caso, o produto final mais desejado no processo do parto é o novo membro social, o bebê; a nova mãe é um subproduto secundário 2 . 0 Brasil hoje vem trabalhando com a visão de um novo paradigma, que é o da atenção humanizada à criança, à mãe e à família, respeitandoas em suas características e individualidades ${ }^{4}$.

Apesar de a gestação ser considerada um processo normal da fisiologia feminina, é um momento especial na vida das mulheres, pois cada uma vivencia a gravidez de forma diferente, experienciando de forma singular as repentinas mudanças decorrentes desta fase nos níveis físico, emocional, social e familiar. Quando uma mulher engravida, ela não o faz só, tratase de uma situação compartilhada com sua família ou grupo social ao qual pertence. Nesse contexto destaca-se a cultura, e é por meio dela que a gestante ou a puérpera expressam suas necessidades, seus valores, seus saberes, suas crenças e sua visão de mundo.

Assim, a cultura inclui conhecimento e práticas influenciadas por fatores como a visão de mundo, a linguagem, a religião, o parentesco, a etno-história, além de fatores políticos, educacionais, tecnológicos e o contexto do meio ambiente no qual ocorre ${ }^{5}$. Neste sentido, o conceito de cultura é complexo em razão de representar uma teia de significados a serem interpretados ${ }^{6}$. Essa pode ser uma influência poderosa no comportamento das pessoas porque é um conjunto de práticas que perduram através do temp $0^{5}$.

Sabe-se que os primeiros contatos entre mãe e filho logo após o nascimento são de extrema importância para a construção e fortalecimento do vínculo afetivo entre os dois. Entretanto, a prática tem nos revelado que este encontro pode ficar extremamente prejudicado, principalmente quando o recémnascido apresenta alguma alteração clínica tais como: prematuridade, malformações congênitas e as complicações que acompanham estas condições. Essas, na maioria das vezes, culminam com a necessidade de internação do bebê em unidade de terapia intensiva neonatal.

A vivência dessa situação de separação inesperada pode provocar o surgimento de sentimentos e emoções que interferem no vínculo afetivo mãe-bebê e na relação familiar. Nesse sentido, tendo em vista a necessidade de reconhecer e atender as demandas de cuidado deste bebê e sua família no ambiente do hospital, considerando o contexto cultural, questionou-se: qual a influência da cultura na vivência da mulher mãe de um recémnascido de risco? E de que forma os profissionais de enfermagem podem atuar, valorizando os saberes herdados culturalmente por essas mulheres?

Com base nessas considerações, o objetivo deste estudo foi compreender a influência do contexto cultural no desenvolvimento da gestação e no cuidado ao bebê de mulheres mães de recém-nascidos de risco.

\section{METODOLOGIA}

Trata-se de um estudo descritivo e exploratório, com uma abordagem qualitativa. Os dados foram coletados de 03/04/ 2007 a 28/05/2007, por meio de entrevista individual, semiestruturada com dez puérperas hospitalizadas em uma unidade materno-infantil que tinham seus filhos recém-nascidos internados na Unidade de Terapia Intensiva Neonatal (UTIN) de uma instituição hospitalar no interior do Rio Grande do Sul. 0 município cenário do estudo teve sua origem marcada pela colonização de imigrantes alemães e possui como característica principal a influência da cultura germânica no local e na região. Possui potencial desenvolvimento industrial, bem como uma forte presença da agricultura, em especial da fumicultura.

Foram incluídas puérperas em qualquer idade, profissão ou condição social que aceitaram livremente participar do estudo no período de puerpério imediato até 96 horas após o parto.

Todos os aspectos éticos foram considerados durante 0 processo da pesquisa de acordo com Resolução 196/96, do Ministério da Saúde 70 projeto foi aprovado pelo Comitê de Ética em Pesquisa da UFSM, sob o número 23081.001434/ 2007-54.

Os dados foram analisados aplicando-se a análise de conteúdo, com ênfase na análise temática ${ }^{8}$. Essa consiste em descobrir os núcleos de sentido que compõem uma comunicação, desdobrada em três etapas: a pré-análise, a exploração do material e o tratamento dos resultados obtidos e a interpretação. 
Práticas Culturais de Cuidados de Mulheres Mães

\section{RESULTADOS E DISCUSSÃO}

Após a análise dos dados, as principais categorias que emergiram foram: o contexto sociocultural influenciando o período gestacional e os saberes populares no cuidado com o bebê.

\section{Caracterização das mulheres mães participantes do estudo}

As dez mulheres participantes do estudo tinham idade entre 21 e 35 anos, todas casadas ou com união estável no momento da entrevista; a maior parte com ensino fundamental incompleto; igualmente procedentes das zonas urbana e rural; as complicações obstétricas de maior incidência foram a amniorrexe prematura e a toxemia gravídica; a principal causa de internação dos recém-nascidos na unidade de terapia intensiva foi a prematuridade; todas as participantes do estudo possuíam uma orientação religiosa, sendo metade delas católicas e metade evangélicas luteranas; a maioria delas referiu possuir origem étnica alemã/portuguesa, seguidas por brasileira/portuguesa.

\section{O contexto sociocultural influenciando o período gestacional}

As mulheres citaram de forma espontânea o planejamento desta gravidez, bem como a situação de saúde, social, emocional e financeira envolvida neste contexto. Assim, $70 \%$ das informantes referiram ter planejado engravidar e $30 \%$ delas referiram sua gravidez como não-planejada e inesperada. Portanto, o planejamento da gravidez foi citado pela maioria das mulheres deste estudo, sendo que algumas delas esperavam ansiosamente por isso.

Das sete mulheres que referiram ter planejado a gravidez, quatro delas disseram que a gravidez transcorreu tranquilamente e sem maiores complicações. A motivação para o trabalho foi um dos fatores referidos como gerador de tranquilidade e bem-estar na gestação. 0 fato de algumas mulheres relacionarem a evolução positiva ou negativa da gestação com a sua disposição para o trabalho pode estar relacionado à cultura alemã, no sentido de que o trabalho é, para as pessoas dessa cultura, fonte de dignidade. Isso pode ser constatado também com as mulheres do estudo. Neste contexto, as pessoas de origem germânica sentem-se extremamente desconfortáveis em depender das outras, pois invariavelmente são elas as provedoras de ajuda, estando acostumadas a manter tudo organizado e sob controle ${ }^{9}$.

Das sete mulheres que esperavam e planejaram a gravidez, três referiram uma gestação conturbada. No contexto de gravidez, essas mulheres apresentaram algum tipo de problema de saúde física, associado a outros de ordem familiar ou emocional. Os problemas de saúde física foram: a hipertensão arterial sistêmica (HAS), associada à ameaça de abor to e/ou à hiperêmese gravídica e ao diabetes. Em relação ao estado emocional delas, todas referiram a presença de "nervosismo" e/ou medo durante a gravidez.
A ameaça de aborto acometeu duas das três mulheres que referiram uma gravidez complicada. Essas revelaram medo da perda durante a gestação. Outra mulher, portadora de diabetes e de HAS, referiu que o motivo da complicação na gravidez era, além da doença, o conflito familiar. 0 diabetes durante a gestação exige da mulher uma intensa e às vezes sobrecarregada rotina de exames laboratoriais, além de um controle rigoroso nos hábitos de vida e alimentação. Isso pode ser percebido de uma forma negativa por essa mulher e assim influenciar negativamente na vivência dessa fase.

No que tange ao convívio familiar durante a gestação, considera-se a gestação, além de um ato biológico, um evento social, que afeta as relações entre o grupo familiar. A gestante traz consigo toda uma identidade de relações socioculturais cultivadas em seu ambiente familiar e ainda recebe influência do meio onde vive, aumentando, assim, sua bagagem de costumes e atitudes relacionadas à gravide $z^{10}$.

As três mulheres que não planejaram engravidar manifestaram que a gestação não havia sido boa, ora pela situação econômica e social, ora por problemas de saúde propriamente ditos, ou ambos. Para Amarílis ${ }^{1}$, o fato de ser solteira na época e ter pouco tempo de namoro com o pai de seu filho, somado ao desemprego de ambos, representou para ela enorme dificuldade de aceitação desta gravidez, conforme 0 discurso a seguir:

Essa gravidez não foi boa, eu não estava esperando ela. Tanto que... até o sexto mês, mais ou menos, eu não queria ela... Depois eu pensei melhor e me arrependi [...] Tu vê, começa a sentir a criança se gerando dentro de ti, se movimentando... Aí eu comecei a entrar neste entendimento... (Amarilis).

Nesse caso, a aceitação da gravidez aconteceu mediante a percepção dos primeiros movimentos fetais, o que, de acordo com alguns estudos, tende a favorecer a aceitação da gravidez. Essa é a primeira vez que a mulher sente o feto como uma realidade concreta dentro de si, como ser separado dela e, no entanto, tão dependente, mas já com características próprias ${ }^{11}$.

Rosa, tabagista e consumidora esporádica de álcool durante a gestação, já havia sido aler tada pelo profissional de saúde (médico), conforme o relato:

Mas não, a gente nunca espera isso... Nunca imaginei que ia ter que passar por isso [...] doutor falava muito, por que eu fumava... Mas eu achava que era bobagem isso, porque como éque dos outros dois eu sempre fumei e nunca deu nada... a minha irmã nunca fumou, nunca bebeu nada... E perdeu 0 nenê [...] deixei pra ver como que ia acontecer... (Rosa).

Nesse caso, percebe-se que essa mulher não conseguiu relacionar o conhecimento científico com a realidade vivida e comprovada 
por ela, ou seja, a não-conjugação do saber popular com o saber profissional. Ressalta-se aqui a capacidade feminina de perceber e responder às sensações do corpo. 0 profissional de saúde abstrai o processo gestacional do restante da experiência de vida da mulher e o trata como um episódio biomédico isolado?.

Dessa forma, de acordo com a visão de mundo e a experiência de Rosa, o ato de fumar ou beber de forma esporádica não prejudicaria o bebê, pelo contrário, poderia até trazer benefícios, conforme a seguir:

\section{[...] isso é coisa dos antigos que diz que é bom tomar um golinho pra o nenê ficar limpinho... E não nascer com aquelas cascas na cabeça... E isso é verdade... Que a gente foi criado assim... (Rosa).}

Em se tratando do uso de tabagismo dessa mulher na gestação, nota-se que, sendo ela fumicultora, o cigarro fazia parte dos costumes e da própria cultura local. Na zona rural, de uma maneira geral, também o uso de álcool pode ser considerado um ato natural, incapaz de provocar maiores problemas. Porém, sabe-se que o tabagismo durante a gestação aumenta o risco de ter aborto espontâneo em $70 \%$ e o bebê nascer prematuro em $40 \%{ }^{12}$.

Em contraponto aos casos anteriores, $40 \%$ das mulheres referiram já esperar o acontecimento do parto prematuro com a consequente possibilidade de internação do seu filho na UTIN. Entretanto, para cada uma delas, isso foi associado a fatores diferentes, tais como: o sentimento ou intuição materna (ressaltado pela idéia de culpa e punição); a história gestacional de três abortos; uma ameaça de aborto associado à hipertensão arterial e ansiedade; e história pregressa de outro filho prematuro, conforme a narrativa de Camélia:

Eu não imaginava que eu ia passar por aquilo de novo... Agora no finalzinho, nesta última semana que eu comecei a me preparar [...] A médica já tinha conversado comigo [...] não é uma experiência boa (Camélia).

Sendo assim, mesmo em uma segunda vivência, a mulher pode não estar preparada e necessitar de apoio dos profissionais de saúde para enfrentar e lidar da melhor forma com a situação que se apresenta. Na fala de Amarilis, percebem-se, como os sentimentos mais evidentes nesses casos, a autopunição e a culpa:

Eu já imaginava, já esperava... De repente foi por este sentimento, por eu ter renegado, e eu imaginei que alguma coisa ia sair errada [...], digamos, eu ia ter que pagar por aquilo... Eu errei por não querer ela, por não ter aceitado ela desde o comecinho... Por ter aceitado ela depois que ela já tava geradinha... Que a gente não se cuida e depois se arrepende... A criança não tem culpa das besteiras dos pais... (Amarilis).

0 sentimento de culpa ou arrependimento da mãe após o nascimento do bebê se enquadra na sequência evolutiva das emoções maternas diante dos bebês com problemas, prematuros ou malformados ${ }^{13}$. Ressalta-se aqui a predominância de fatores emocionais e sociais interferindo diretamente na saúde de mãe-filho, um dos problemas bastante atuais em nossa sociedade.

Dessa forma, torna-se imprescindível reconsiderar os fatores que nor teiam a identificação de uma gestação de alto risco, tais como o psicológico-emocional, social e o contexto cultural das mulheres.

\section{Os saberes populares na prática de cuidado com o bebê}

As orientaç̃̃es aos pais sobre os cuidados com o RN de risco após a alta hospitalar da UTIN são, muitas vezes, negligenciados pela enfermagem. Isso parece acontecer também devido à falta de um consenso entre os profissionais de saúde sobre essas informações. Assim, $90 \%$ das mulheres que fizeram parte deste estudo afirmaram que não sabiam como cuidar deste bebê de risco em casa, e apenas uma referiu conhecimentos sobre esses cuidados, por ter uma experiência prévia.

A maioria das mulheres mostrou-se insegura ante esta questão, esperando esclarecimento na medida em que se aproximava o momento da volta ao lar. Muitas vezes elas demonstraram saber que os bebês necessitariam de cuidados especiais. A avó do bebê foi referida como uma pessoa com experiência e que poderia ajudar nos cuidados com ele após a alta hospitalar. Rosa mencionou atenção especial aos cuidados com o banho e com o coto umbilical, conforme a seguir:

[...] no umbiguinho eu botava um pouco de banha de galinha... Os médicos mandavam colocar merthiolate, mas como é que eu ia botar isso daí? Botava banha de galinha depois do banho e caia bem ligeiro... Porque a mãe nos criou todos assim... Eum mais forte do que o outro... Não sei... Eu gosto disso... (Rosa)

A crença é uma fé, acreditar no dito e no ouvido no cotidiano é incorporar este pensamento. Na verdade, a crença revela a forma de ser de quem a possui ${ }^{9}$. Apenas Camélia demonstrou ter adquirido conhecimentos sobre os cuidados com bebê de risco; isso devido a sua vivência anterior com outro filho. Ela disse não concordar com certas recomendações profissionais, como, por exemplo, o não-uso de faixa umbilical e da chupeta. Para ela, o uso da chupeta acalma a criança, pensamento decorrente de sua experiência como professora de educação infantil, conforme a seguir: 
Práticas Culturais de Cuidados de Mulheres Mães Iserhard ARM, Budó MLD, Neves ET, Badke MR

\section{[...] A gente sabe que no hospital eles não deixam dar, né... Eu vou dar o bico em casa... Eu considero que a criança que chupa bico, como eu já tive escolinha, a criança é bem mais calma... Do que a criança que não chupa... A criança ir pra escolinha sem bico é uma tortura para as tias... (Camélia)}

Neste contexto, o uso da chupeta e da mamadeira é amplamente combatido por profissionais de saúde; no entanto, mesmo sabendo sobre as normas atualmente institucionalizadas nos Hospitais "Amigo da Criança", as mulheres continuam a introduzir seu uso ${ }^{10}$.

Considerando a amamentação uma prática híbrida naturezacultura ${ }^{14}$ na qual estão envolvidas as diversas dimensões de vida da mulher, é possível pensar que as normas institucionais que buscam desencorajar o uso da chupeta, a partir de uma retórica profissional e científica, não estão atingindo seu objetivo, pois esbarram nas concepções da comunidade atendida, que superam as proibições e mantêm suas razões para a oferta desse artefato ${ }^{15}$.

Desde os primórdios da humanidade, o ser humano utiliza práticas alternativas para manter a saúde ou livrar-se de doenças. Assim, esse foi um dos domínios mais significativos, sob o ponto de vista cultural, adotados pelas puérperas, emergindo uma gama de recursos populares, utilizados por elas, para o cuidado próprio e do bebê. Dentre eles, um dos temas mais frequentes foi a benzedura, referida pela maioria das puérperas.

Para Tulipa, a benzedura era executada por sua mãe que benzia de tudo, quebranto, dor de barriga, além de conhecer simpatias para cortar o soluço na criança.

Nesse contexto cultural, a benzedura é um aprendizado adquirido por pessoas próximas à puérpera, geralmente familiares. As práticas alternativas de atendimento à saúde ocorrem entre pessoas ligadas umas as outras por laços de parentesco, amizade, ou residência, o que significa que 0 paciente e a benzedeira compartilham concepções semelhantes sobre saúde e doençą2.

Nos relatos desse estudo, a prática da benzedura relacionada com o dito mal dos sete diasfoi marcante. Segundo as mulheres entrevistadas, deve haver resguardo da mulher, e não se deve sair de casa neste período, pelo risco de ter a recaída. Alguns rituais envolvendo práticas de benzeduras foram descritas, conforme segue:

\section{[...] a mãe tem uma coisa que ela fala com a lua cheia... Na primeira lua cheia depois do nenê nascer é pra mostrar o bebê para a lua... Ela diz que é pra não pegar mal no bebê... (Rosa).}

A prática da benzedura para costela pegada também foi descrita pelas puérperas. A costela pegada, segundo elas, tem um diagnóstico difícil e somente pode ser identificado por aqueles que entendem do assunto, neste caso suas próprias mães. Uma delas revelou que sua mãe era uma pessoa muito experiente e supersticiosa, conhecedora do comportamento dos bebês, conforme a seguir:
Esc Anna Nery Rev Enferm 2009 jan-mar; 13 (1): 116-122

[...] uma vez uma criança tava chorando, chorava, chorava... Aí eu disse assim pra mãe, olha eu acho que isso é costela pegada, né? Ai a mãe ficou meio assim e levou no médico, né... Daía médica disse que não... Que isso era coisa dos antigos... A costela pegada que eles dizem é cólica intestinal... Que dói assim, não sei o quê... (Camélia).

Entretanto, esta mulher também revelou que sua mãe, em outra oportunidade, fez o diagnóstico preciso, confirmado pelos médicos depois, de uma criança que chorava em demasia e não sofria de costela pegada, mas sim de pneumonia.

A rezadeira ou benzedeira reza para quebranto, e para outros incômodos das crianças. Ainda existe uma tríade essencial para entender a relação da população com 0 benzedor: a fórmula da bênção, a fé na cura que é dom de Deus e a confiança da comunidade no curador. Esses são pontos de suma importância para que haja uma eficácia nesse tipo de prática popular ${ }^{16}$.

Outro elemento cultural muito importante e significativo para a maioria das puérperas sobre as práticas culturais para o cuidado com os bebês foi o uso dos chás. Esse consistiu no primeiro recurso utilizado por elas diante de uma situação de cólica ou febre no bebê. Duas mulheres referiram que as suas mães entendiam muito bem sobre este assunto e por isso iriam usar os chás com a ajuda e explicação materna. Veja a seguir

[...] É... chazinho a gente tem o costume de dar... Por mais que a gente saiba que amamentando não precisa, né. Mas ah, vou experimentar para este não dar... Eu já sei que não precisa, mas a mãe diz que não... Eles sentem sede, é bom dar um chazinho... (Camélia).

Neste contexto, as famílias de condições socioeconômicas desfavoráveis, pelas suas dificuldades de acesso aos serviços formais de saúde, são levadas a utilizar com muita frequência as alternativas populares na busca de soluções para a doença. Embora existam muitas práticas alternativas nos cuidados de saúde, o uso de ervas medicinais é um recurso tradicional nas famílias, e a maioria dos usuários as cultiva nos próprios quintais de sua casa $^{17}$.

Em relação ao uso caseiro de plantas medicinais, destacase sua influência no tratamento de problemas de saúde de crianças. Os chás caseiros quase sempre são oferecidos às crianças desde os primeiros tempos de vida, com a intenção de amenizar ou resolver situações de desconforto ou doença. Entretanto, apesar de não recomendadas, algumas práticas populares de saúde continuam a fazer parte do cotidiano de mães no cuidado de suas crianças, porque estão pautadas na vivência, na experimentação e na avaliação do sucesso de sua adoção diante de problemas de saúde ${ }^{18}$. 
A espiritualidade pode ser considerada como algo inerentemente humano e fortemente ligado às práticas culturais para a saúde. Assim, a fé em Deus e as orações para os recémnascidos foram apontadas por duas puérperas como o único ritual que costumavam seguir, sendo estas duas evangélicas. Para elas, a fé em Deus e na Sua vontade constituíam a sua crença e eram suficientes para a melhoria de saúde do seu bebê.

0 cuidado com o coto umbilical também emergiu, denotando uma ligação muito forte com a cultura local e as práticas culturais para o cuidado dos bebês. Assim, o uso da faixinha ao redor do umbigo apareceu no discurso de três mulheres; para elas, a faixinha evitava o aparecimento de hérnia no caso de a criança ser muito chorona. 0 uso da faixa umbilical foi uma prática muito comum, e seu uso era transmitido de geração em geração. Atualmente, ela é contraindicada devido à comprovação científica sobre a sua ineficácia e até mesmo nocividade para a criança, em alguns casos.

Uma das mães declarou que faria uso da faixa umbilical em seu filho, pois de acordo com sua experiência anterior, foi eficiente:

\section{[...] Algumas coisas eu não aceito o que a saúde coloca... eu vou colocar faixa no umbigo do meu filho... porque na outra filha eu não coloquei e ela saiu do hospital como quase dois centímetros de umbigo saltado pra fora... daímeu marido disse: 'dá um jeito'... Então eu coloquei a faixinha e quando tirei tava no lugar (Camélia).}

Esta mulher referiu ainda que sua mãe, sua sogra e suas irmãs fazem uso da faixinha nos bebês, e que quando uma amiga sua engravida ela aconselha colocar a faixa em seu filho. Esta convicção pode ser reforçada pelo fato de ter tido um problema de hérnia quando era nenê, o qual atribui ao não-uso da faixa, associado ao fato de ela ter sido muito chorona.

Algumas vezes o costume se relaciona, não com o coto umbilical em si, mas com aquele pedaço de cordão que se desprende depois de seco, como no caso de Rosa:

\section{[...] cuidar o umbigo, depois que ele cair, a gente tem que enterrar. Porque se não o rato come e a criança vira ladrão...}

Dessa forma, em relação às alternativas de cuidados populares com o bebê, as mulheres citaram principalmente a benzedura e suas variações, o uso de chás de ervas, a religiosidade e as orações, e os cuidados com o coto umbilical, tais como o uso da faixa ao redor do umbigo.

Diante do que foi exposto, nota-se o quão relevante é para o enfermeiro conhecer as alternativas de cuidado popular, bem como perceber o quanto estas estão inseridas no contexto de cuidado próprio das famílias. Esse tipo de conhecimento auxiliará no desenvolvimento de estratégias significativas de prover cuidado e promover a saúde, respeitando os costumes, as crenças e os rituais das famílias, valorizando os significados dos eventos para cada uma delas e permitindo a sua participação no processo de cura dos indivíduos e de adaptação às situações de crise.

\section{CONCLUSÕES E IMPLICAÇÕES PARA A PRÁTICA}

$\mathrm{Na}$ tentativa de compreender a influência do contexto cultural no desenvolvimento da gestação e no cuidado ao bebê de mulheres mães de recém-nascidos de risco, concluiu-se que a experiência vivenciada pelas mulheres está intimamente relacionada aos significados e representações que emergem do contexto cultural dessas mulheres. 0 fato de ter um bebê de risco que necessita ser hospitalizado em UTIN é um momento de crise para a família e, principalmente, para esta mãe em seu pós-parto.

Pelo exposto, sugere-se que esta mulher, mãe de um recémnascido de risco, seja assistida pelos profissionais de enfermagem munidos de elementos que viabilizam a prática de um cuidado singular, centrado nas crenças, valores e estilos de vida de cada mulher e sua família.

Outro aspecto que podemos salientar refere-se à invisibilidade da enfermeira nas afirmativas; quando foi citada, isso ocorreu em uma situação pouco significativa. Desta forma, apesar de estar presente nos diferentes cenários de atenção, não foi identificada, e sequer mencionada como tendo contribuído para a assistência à gestante/parturiente/puérpera. Os achados apontam, ainda, que não houve, na maioria das vezes, a compreensão da mulher em seu todo, sua visão de mundo, sua maneira de pensar, sentir e agir.

Pontua-se que, em questões de conflito entre 0 conhecimento popular e o profissional, prevaleceu o saber profissional em detrimento da valorização da experiência/ vivência das mulheres, revelando-se, assim, a imposição cultural referida por Leininger ${ }^{5}$.

Por fim, destaca-se a necessidade de aproximação entre o saber da família - popular e o saber científico - profissional, valorizando as experiências/vivências prévias das mulheres mães de bebês de risco internados em UTIN, pois estas estão intimamente imbricadas com o contexto cultural das mesmas. Diante disso, evidencia-se a contribuição do presente estudo no que se refere à importância da aliança dos saberes popular e acadêmico, possibilitando a reconstrução do conhecimento sobre práticas complementares de saúde. 


\section{REFERÊNCIAS}

1 Ministério da Saúde (BR). Secretaria de Políticas de Saúde. Área Técnica da Saúde da Mulher. Parto, aborto e puerpério: assistência humanizada à mulher. Brasilia: DF; 2001.

2 Helman CG. Cultura, saúde e doença. $4^{\mathrm{a}}$ ed. Porto Alegre (RS): Artmed; 2003.

3 Riessman, CK. Women and medicalization: a new perspective. Social Policy 1983;14( 1) 3-18.

4 Ministério da Saúde (BR). Atenção humanizada ao RN de baixopeso. Método Canguru. Manual Técnico. Brasília(DF); 2002.

5 Leininger M A. Culture care diversity and universality: a theory of nursing. New York(USA): National League for Nursing Press; 1991.

6 Roehrs H, Lenardt MH, Maftum MA.Práticas culturais familiares e 0 uso de drogas psicoativas pelos adolescentes: reflexão teórica. Esc Anna Nery Rev Enferm 2008 jun;12 (2): 353 -57.

7.Ministério da Saúde (BR). Conselho Nacional de Saúde. Comissão Nacional de Ética em Pesquisa. Resolução no 196 de 10 de outubro de 1996: diretrizes e normas regulamentadoras de pesquisa envolvendo seres humanos. Brasília (DF); 1996.

8 Minayo MCS. 0 desafio do conhecimento: pesquisa qualitativa em saúde. $8^{a}$ ed. São Paulo (SP): Hucitec; 2004.

9 Waldow VR. Cuidado humano: o resgate necessário. Porto Alegre (RS): Sagra Luzzatto; 1998.

10 Baruffi LM. 0 Cuidado cultural à mulher na gestação. Passo Fundo (RS): UPF; 2004.
11 Maldonado MT. Psicologia da gravidez: parto e puerpério. Petrópolis (RJ): Vozes; 1994.

12 Ministério da Saúde (BR). Controle dos cânceres do colo de útero e da mama. Braślia (DF); 2006. Cadernos de Atenção Básica, 13.

13 Rugolo LMSD, Bottino J, Scudeler SEM, Bentlin MR, Trindade CEP, Perosa GB, Junior AR. Sentimentos e percepções de puérperas com relação à assistência prestada pelo serviço materno-infantil de um hospital universitário. Rev Bras Saude Mater Infant 2004 out/dez; 4 (4): 423-33.

14 Almeida JAG. Amamentação: um híbrido natureza-cultura. Rio de Janeiro (RJ): Fiocruz; 1999.

15 Sertório SCM, Silva IA. As faces simbólica e utilitária da chupeta na visão de mães Rev Saude Publica 2005 abr; 39 (2): 156-62.

16 Freitas MA. Assistência de enfermagem à gestante: resultados de uma intervenção fundamentada em um modelo de educação de adultos [tese de doutorado]. São Paulo (SP): Universidade Federal de São Paulo; 1999.

17 Silva YF. Família e redes sociais: o uso das práticas populares no processo saúde e doença. In: Silva YF, Froenço MC. Saúde e doença: uma abordagem cultural da enfermagem. Florianópolis (SC): PapaLivro; 1996. p.75-93.

18 Medeiros LCM. As plantas medicinais e a enfermagem: a arte de assistir, de curar, de cuidar e de transformar os saberes [tese de doutorado]. Rio de Janeiro (RJ): Escola de Enfermagem Anna Nery/ UFRJ; 2001. 